\title{
Falciparum malaria masquerading as appendicitis
}

\author{
Anand Kumar Bhardwaj, P D Sharma, Akshay Sharma \\ Department of Paediatrics, MM Institute of Medical Sciences and Research, Ambala, India \\ Correspondence to Dr Anand Kumar Bhardwaj, col.akbhardwaj@gmail.com
}

\begin{abstract}
Summary
The incidence of falciparum malaria is very high in India. Falciparum malaria is a multiorgan disease which can present with extremely varied presentations. The severity of the disease and difficulty in its diagnosis require a keen sense of suspicion on the part of the treating physician to diagnose it. Here is an unusual case of falciparum malaria presenting as acute appendicitis. This case did not respond to artemether therapy and that also points towards drug resistance emerging in malaria. The child was operated upon and appendix was found to be inflamed. After a tumultuous postoperative course with symptoms suggestive of acute renal failure, a diagnosis of falciparum malaria was made and quinine started. Recovery was uneventful thereafter.
\end{abstract}

\section{BACKGROUND}

The number of confirmed malaria cases reported in the South-East Asia Region in 2009 was 2.7 million, and malaria claimed 3188 lives that year in this region. ${ }^{1}$ Sixty per cent of these cases were caused by Plasmodium falciparum. ${ }^{1}$ In India, diagnosis of malaria is predominantly empirical, and light microscopy of thick and thin films remains the 'gold standard' for diagnosis. However, a lot of factors such as timing of blood collection, preparation of blood smear and examination of slides by a skilled microscopist preclude to frequent misdiagnosis. At the same time, malaria sometimes has a very complex presentation which can mimic several other diseases. ${ }^{2}$ The high number of cases and the elusive diagnosis of malaria make it a major public health problem in South Asia.

We report an unusual case of falciparum malaria presenting as acute appendicitis which evaded diagnosis and also raised questions over the increasing drug resistance emerging in malaria.

\section{CASE PRESENTATION}

A 9-year-old male child presented to a service hospital of North India with complaints of pain abdomen and fever for 2 days. Pain abdomen was localised to the epigastric and periumbilical regions in the beginning but gradually became diffuse. The child's parents complained high grade fever with chills and rigors. The patient also had history of a few episodes of vomiting prior to admission.

The child weighed $26 \mathrm{~kg}$, was $97 \mathrm{~cm}$ tall and was well built and nourished. At presentation, the child was febrile $\left(102{ }^{\circ} \mathrm{F}\right)$, had tachycardia (128 beats/min) and blood pressure was 106/64 mm Hg. Pallor was present. Abdomen was diffusely tender all over, but marked tenderness was noted over right iliac fossa. There was no organomegaly. Bowel sounds were normal.

Considering it to be a case of acute abdomen, a surgical consultation was sought. A provisional diagnosis of acute appendicitis was made. Abdominal ultrasound was unequivocal hence it was decided to undertake a diagnostic laparoscopy and guided laparotomy. The preoperative investigations suggested anaemia (haemoglobin $7.0 \mathrm{~g} \%$ ) and leucopenia (total leucocyte count 2800). Peripheral smear was positive for Plasmodium vivax.

Broad spectrum antibiotics were initiated. In view of presence of $P$ vivax in peripheral smear, injection artemether was started since the patient had been advised to be nil per orally.

Preoperatively, fluid collection was found in the para colic gutter. There was no evidence of peritonitis. Appendix was found to be inflamed and was excised. Postoperatively patient was transferred to the intensive care unit. In the next $24 \mathrm{~h}$, the patient had passed only $210 \mathrm{ml}$ urine (oliguria) and was having difficulty in breathing (tachypnoea). Renal parameters were deranged (urea $96 \mathrm{mg} \%$, creatinine $1.5 \mathrm{mg} \%$ ). A repeat examination of peripheral smear was done and $P$ falciparum gametocytes were seen. Diagnosis was revised to complicated falciparum malaria with coinfection of vivax malaria.

During the following $24 \mathrm{~h}$, urine output reduced to 115 $\mathrm{ml}$. Patient had developed severe oliguria unresponsive to diuretics. Respiratory failure was setting in requiring continuous $\mathrm{O}_{2}$ administration. Hypotension (90/56 mm Hg) ensued requiring vasopressor support. Haemoglobin had dropped to $5.7 \mathrm{~g} \%$, and there was appearance of icterus with rise in serum bilirubin, liver enzymes and prolongation of prothrombin time. Gastrointestinal (GI) bleed was indicated by malaena. Urine examination showed microscopic haematuria and proteinuria. Despite the appearance of multiorgan dysfunction, patient remained afebrile. Renal output gradually improved but azotemia persisted.

Surprisingly, there was reappearance of fever on fifth day. At this point of time peripheral smear was repeated which was still positive for the $P$ falciparum. There was a doubt about the resistance to artemether which prompted the addition of quinine. Patient's condition improved rapidly thereafter. Fever subsided within 2 days of starting 
quinine and azotemia also improved. Child was soon off the vasopressor support. On the ninth day of admission, the peripheral smear was negative for the $P$ falciparum and $P$ vivax.

\section{OUTCOME AND FOLLOW-UP}

The recovery was gradual and complete.

\section{DISCUSSION}

Incidence of falciparum malaria is very high in India. ${ }^{1}$ It has high morbidity and mortality and presents with varied manifestations. ${ }^{3}$ Paroxysms of fever with chills and rigor at regular intervals are the classical symptoms of malaria. But falciparum malaria is a multisystem disorder which may present with acute lung injury, meningitis, hepatitis and fulminant hepatic failure, acute gastroenteritis, to Guillain-Barre syndrome, cerebellar symptoms, psychosis and even urticaria, with or without rash. ${ }^{3-9}$ Clinical presentation of falciparum malaria may also vary in an individual depending upon the level of parasitaemia and immune status of the patient. ${ }^{10}$ In view of such wide variability in clinical symptoms and presentation, it is necessary on the part of the treating physician to have a keen sense of suspicion.

This patient was a unique case as it presented with symptoms suggestive of acute appendicitis. Though GI symptoms have been described in literature in children with malaria, there have been very few cases where patient has mimicked acute appendicitis. Another important feature to be noted is that this patient exhibited resistance to artemether, as the patient failed to clear the parasitaemia even after 5 days. This necessitated switching back to quinine as a rescue measure. It clearly sends a message against the rampant (mis)use of artemether.

Difficulty in diagnosis and the drug resistance seen in this case led to delay in initiating therapy by 7 days. However, the child recuperated well both from malaria as well as the surgery and had an uneventful recovery.

\section{Learning points}

- Malaria can present in several different forms other than the classical symptoms of fever with chills.

- Falciparum malaria caused by $P$ falciparum is a multiorgan disease which can have severe manifestations and hence requires quick diagnosis and therapy.

- Resistance to antimalarials is increasing and can be primary as well as secondary.

- Light microscopy of blood smear which is currently the 'gold standard' for diagnosis of malaria has several prerequisites to be able to detect the parasitaemia.

- The physicians in malaria endemic areas should consider malaria as a differential diagnosis in each case presenting with fever no matter what other symptoms might be.

\section{Competing interests None.}

Patient consent Obtained.

\section{REFERENCES}

1. WHO. Malaria: Disease Burden in SEA Region. http://www.searo.who.int/en/ Section10/Section21/Section340_4018.htm (accessed 10 January 2011).

2. Wilairatana $\mathbf{P}$, Looareesuwan $\mathrm{S}$. Guideline in management of severe malaria. $J$ Indian Med Assoc 2000;98:628-31.

3. Chandar V, Mehta SR, Sharma PD, et al. Falciparum malaria. Indian J Pediatr 1989;56:365-9.

4. Asiedu DK, Sherman CB. Adult respiratory distress syndrome complicating Plasmodium falciparum malaria. Heart Lung 2000;29:294-7.

5. Durrani AB, Durrani IU, Nawaz A. Cerebral malaria or meningitis? J Coll Phys Surg Pak 1998:8:117-18.

6. Ahsan T, Rab SM, Shekhani MS. Falciparum malaria or fulminant hepatic failure? J Pak Med Assoc 1993;43:206-8.

7. Kyriacou DN, Spira AM, Talan DA, et al. Emergency department presentation and misdiagnosis of imported falciparum malaria. Ann Emerg Med 1996;27:696-9.

8. Wije-sunere A. Guillain-Barre syndrome in falciparum malaria. Postgrad Med J 1992;68:376-7.

9. Sowunmi A, Ohaeri JU, Falade CO. Falciparum malaria presenting as psychosis. Trop Geogr Med 1995:47:218-19.

10. Mahmood K, Jairamani KL, Abbasi B, et al. Falciparum malaria: various presentations. Pak J Med Sci 2006;22:234-7.

This pdf has been created automatically from the final edited text and images.

Copyright 2011 BMJ Publishing Group. All rights reserved. For permission to reuse any of this content visit http://group.bmj.com/group/rights-licensing/permissions.

BMJ Case Report Fellows may re-use this article for personal use and teaching without any further permission.

Please cite this article as follows (you will need to access the article online to obtain the date of publication).

Bhardwaj AK, Sharma PD, Sharma A. Falciparum malaria masquerading as appendicitis. BMJ Case Reports 2011;10.1136/bcr.01.2011.3742, date of publication

Become a Fellow of BMJ Case Reports today and you can:

- Submit as many cases as you like

- Enjoy fast sympathetic peer review and rapid publication of accepted articles

- Access all the published articles

- Re-use any of the published material for personal use and teaching without further permission

For information on Institutional Fellowships contact consortiasales@bmjgroup.com

Visit casereports.bmj.com for more articles like this and to become a Fellow 